\title{
On the Design of Tree-type Ultra Wideband Fractal Antenna for DS-CDMA System
}

\author{
Raj Kumar and Prem Narayan Chaubey (M.Tech. Student) \\ Microwave and Millimeter wave Antenna Lab. \\ Defence Institute of Advanced Technology (DU), Girinagar, Pune-411025 \\ Email: omnamhshivay2010@gmail.com
}

\begin{abstract}
This article describes the CPW-feed ultra wideband tree type monopole fractal antenna and it's backscattering. The prototype antenna is fabricated with optimized dimension. The experimental result of this antenna exhibits the ultra wideband characteristics from 5.0 GHz to 14.0 GHz. The experimental and simulated results are in good agreement. The effects of various design parameters on impedance bandwidth have also been studied in detail using EM simulator. The nature of $H$ and $E$ - plane radiation patterns are omni-directional and bidirectional respectively. The measured group delay is almost constant throughout band. This indicates the phase linearity. The monostatic RCS of antenna is also simulated iteration-wise for antenna and structural scattering mode. This antenna can be useful for UWB system, Microwave Imaging and vehicular radar and military high data rate wireless communications.
\end{abstract}

Index Terms - Planar Monopole antenna, Fractal Geometry, CPW- Feed, Group Delay and UWB system and backscattering.

\section{INTRODUCTION}

The Ultra wideband (UWB) technology opens new door for wireless communication system, since the current wireless system increasing exponentially. Recently, UWB technology with an extremely wide frequency range has been proposed for imaging radar, communications, and localized applications [1]. In 2002, Federal Communication Commission (FCC) authorized unlicensed use of UWB band ranging from $3.1 \mathrm{GHz}$ to $10.6 \mathrm{GHz}$. In this, there are two main approaches for UWB system i.e MB-OFDM (Multi-Band Orthogonal Frequency Division Multiplexing) and DS-CDMA (Direct-Sequence Code Division Multiple Access). The DS-CDMA approach uses three spectral modes of operation, low band (3.1-5.15 GHz), high band (5.825-10.6 GHz), and multi-band (low band plus high band) while MB-OFDM approach divides its full band 3.1-10.6 GHz into 14 subbands with each bandwidth of $528 \mathrm{MHz}$. Each sub-band consists of 128 tones and is modulated with OFDM. The DS-CDMA approach uses high band $(5.825 \mathrm{GHz}-10.6 \mathrm{GHz})$ as a mandatory mode [23]. In this article, we will focus on the UWB antenna design for the DS-CDMA system over the frequency range $5.825 \mathrm{GHz}-10.6 \mathrm{GHz}$ with omni-directional radiation pattern, constant group delay and phase linearity. 
In the open literature, many planar monopole antennas for multiband and UWB have been reported [4-10]. Werner et. al. [5] and N. Cohen [6] have reported the multiband antenna using fractal geometry. The fractal geometry has space filling and self-similarity properties. The space filling properties of fractal geometry is reported in [7] and is useful to reduce the antenna size. While selfsimilar properties of fractal offers the multiband/UWB feature of antenna. Several UWB fractal antennas with CPW-feed have also been reported so far [8-10] using fractal properties. The RCS of the UWB fractal antenna is also necessary to study to predict the antenna potential for military applications. It is reported that antenna scattering is significantly contribute to the total radar cross section (RCS) of low - observable platforms. The antenna scattering is related with its feed port termination. This scattering may be the problem for the design of antenna with low RCS and good radiation characteristic simultaneously [11-12]. So, it is essential to design low RCS antenna with good radiation pattern. The UWB antenna with low RCS is useful for many applications such as UWB radars, military high data rate wireless communications etc.

This article discusses the proposed antenna with detail parametric studies and its backscattering. The antenna has been implemented experimentally. The experimental and simulated results are in good agreement. The radiation patterns, group delay, phase linearity, and peak gain have been discussed. The backscattering of antenna has also been discussed and calculated in operating band. This antenna can be used for frequency band from $5.825 \mathrm{GHz}-10.6 \mathrm{GHz}$ along with wireless local area network (WLAN), secure transmission and military high data rate wireless communications.

\section{ANTENNA GEOMETRY}

The proposed antenna with each iteration is shown in Fig. 1. The antenna geometry has been initiated with 12 dimensional structures (Dodecagon) of side length $2.524 \mathrm{~mm}$ as shown in Fig. 1a. In each side length of 12 dimensional structures, a pentagonal with side length of $1.468 \mathrm{~mm}$ is connected as shown in Fig. 1b. This is the base of antenna structure or called zeroth iteration. In the $1^{\text {st }}$ iteration, the initial base structure is scales down with factor of 0.74 . This scale down structure is subtracted from initial base structure. This is the $1^{\text {st }}$ step of $1^{\text {st }}$ iteration. After this, the initial structure is scale down by 0.58 in $\mathrm{x}$ and $\mathrm{y}$ co-ordinates and united with the first step of $1^{\text {st }}$ iteration. This is called the $1^{\text {st }}$ iteration of the antenna. In $2^{\text {nd }}$ iteration, the $1^{\text {st }}$ iterative structure has been scale down by the factor of 0.58 and united with $1^{\text {st }}$ iterative structure. This is called the step in $2^{\text {nd }}$ iteration. Then the zeroth iteration structure has been scale down twice with the scale factor of 0.58 and united with step. This is called the $2^{\text {nd }}$ iteration of antenna as shown in Fig. 1d. After this the process is repeated in similar fashion for third iteration. The third iteration of final antenna structure is shown in Fig. 1e. This tree-type fractal antenna structure is fed with CPW-feed. The proposed antenna with CPW-feed is shown in Fig. 2 with optimized dimension. 

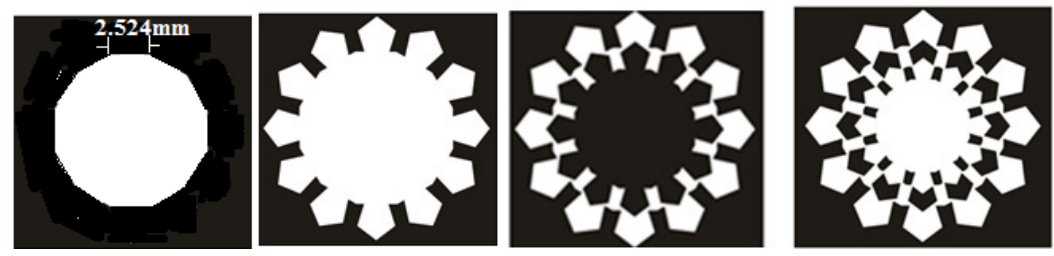

a) 12 Dimension structure

b) $0^{\text {th }}$ Iteration $\quad 1^{\text {st }}$ Step

c) $1^{\text {st }}$ Iteration

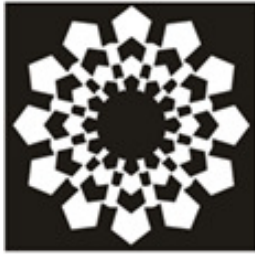

$2^{\text {nd }}$ Step

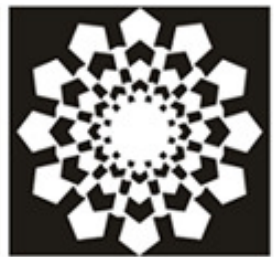

d) $2^{\text {nd }}$ Iteration

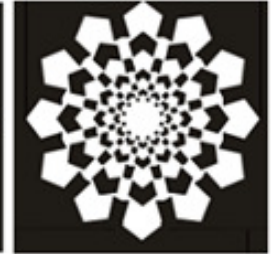

e) $3^{\text {rd }}$ Iteration

Fig. 1. Iteration wise fractal antenna

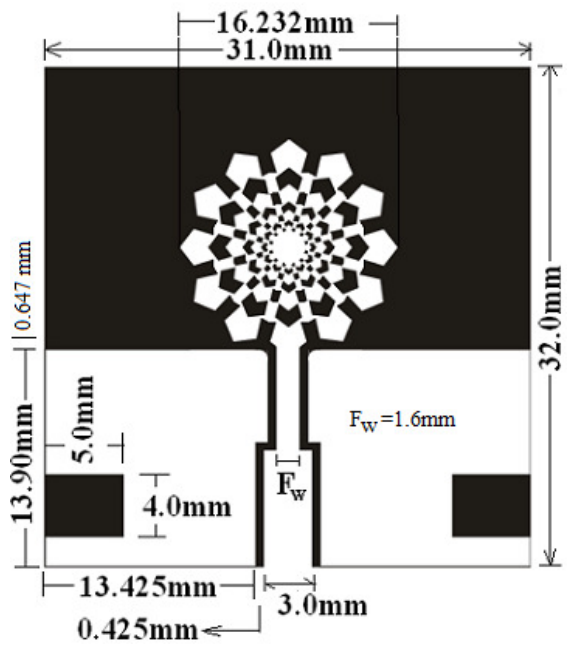

Fig. 2. Proposed tree- type fractal Antenna

III.

\section{EFFECT OF DESIGN PARAMETERS}

The proposed tree-type fractal antenna has been simulated with respect to design parameters and a detail study has been done. It is understood that current distribution over the antenna plays the main role to design the UWB antenna. The current distribution over the antenna at $6 \mathrm{GHz}$ is shown in Fig. 3. The current distribution on the antenna is along the edges of the patch, on the ground near the patch along $\mathrm{x}$-axis and along the length of ground near feed. Keeping in view the current distribution, the gap between patch and ground, gap between feed width and ground, ground width and circumference of patch are critical to achieve the desire impedance matching in the operating band. 


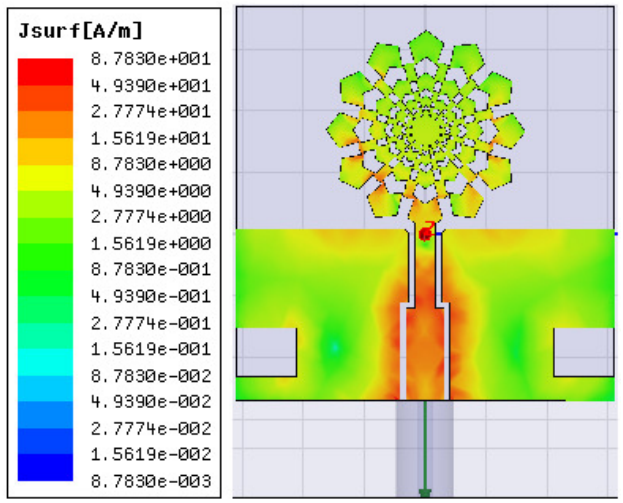

Fig. 3. Current distribution at $6 \mathrm{GHz}$

\section{A. Effect of each iteration}

The proposed tree-type fractal antenna has been simulated using HFSS10 with respect to each iteration. The simulated results are shown in Fig. 4. It is clear from the simulated results as the iteration increases, there is little variation in first resonant frequency to lower frequency side as well as improvement in reflection coefficient at the lower and higher frequency side. This improves overall impedance bandwidth of antenna to some extent. In this, third iterative antenna is fabricated with optimized dimension to validate with simulated result.

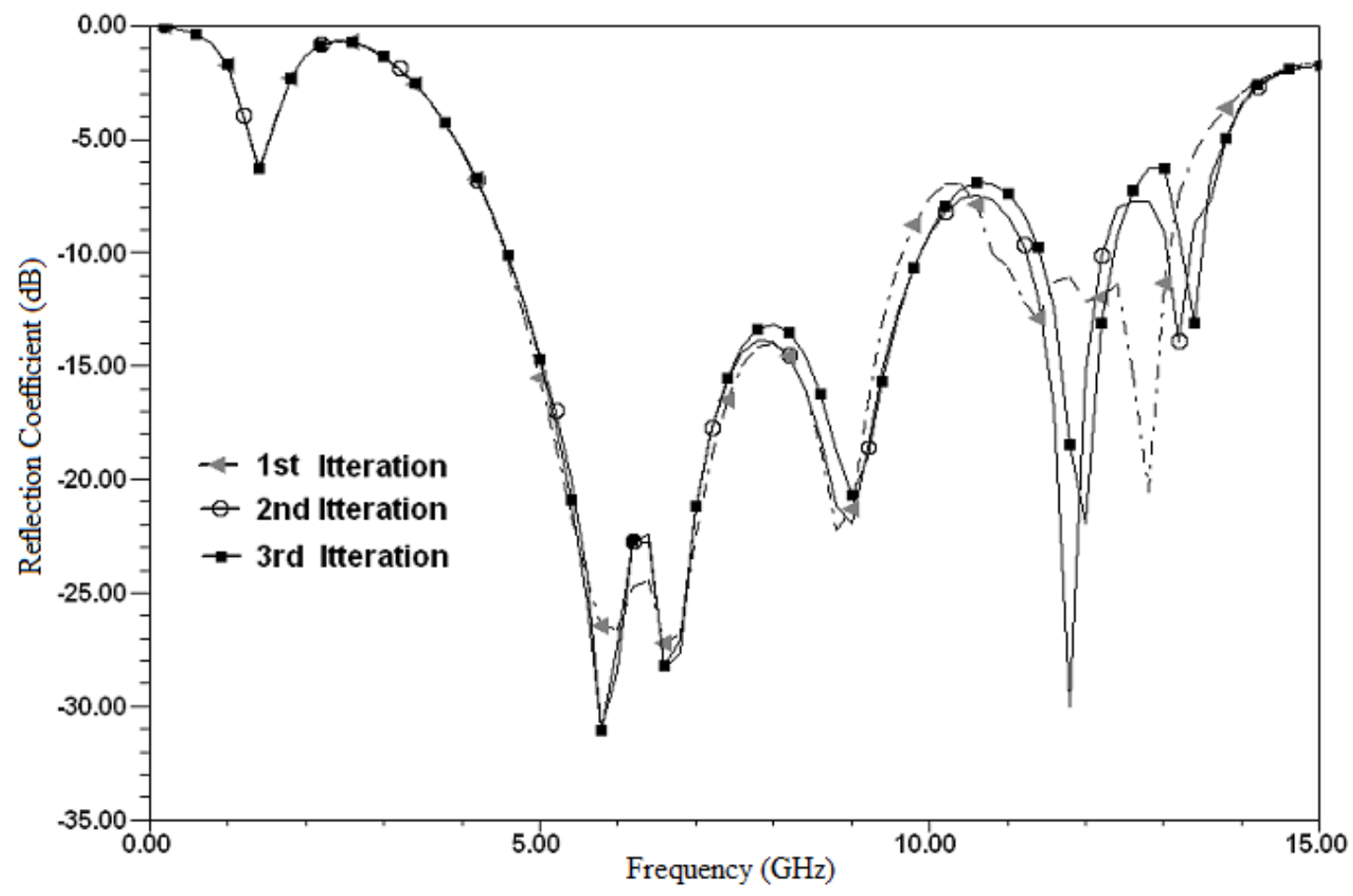

Fig. 4. Simulated results of each iteration of antenna

B. Effect of the Gap between feed and ground 
The proposed tree-type antenna is simulated for gap between feed width and ground. This gap is important for input matching to the radiating element. The proposed antenna has been simulated for various value of the gap between feed and ground with the step of $0.1 \mathrm{~mm}$ from $0.275 \mathrm{~mm}$ to 0.575 $\mathrm{mm}$. The simulated results are shown in Fig. 5. The effect of the gap is clearly visible in the simulated results. The optimum value of gap has been achieved $0.475 \mathrm{~mm}$. The feed width has been optimized in two step i.e near coaxial connector $\mathrm{W}=3.0 \mathrm{~mm}$ and near the patch $\mathrm{FW}=1.6 \mathrm{~mm}$. Initially value of feed width and gap for optimization have been taken $\mathrm{W}=3.2 \mathrm{~mm}$ and $\mathrm{G}=0.275 \mathrm{~mm}$. For this optimized $\mathrm{G}=0.475 \mathrm{~mm}, \mathrm{~W}=3.0 \mathrm{~mm}, \mathrm{Fw}=1.6 \mathrm{~mm}$ and fixing other parameters, the reflection coefficient is achieved better than $-10 \mathrm{~dB}$ throughout band.

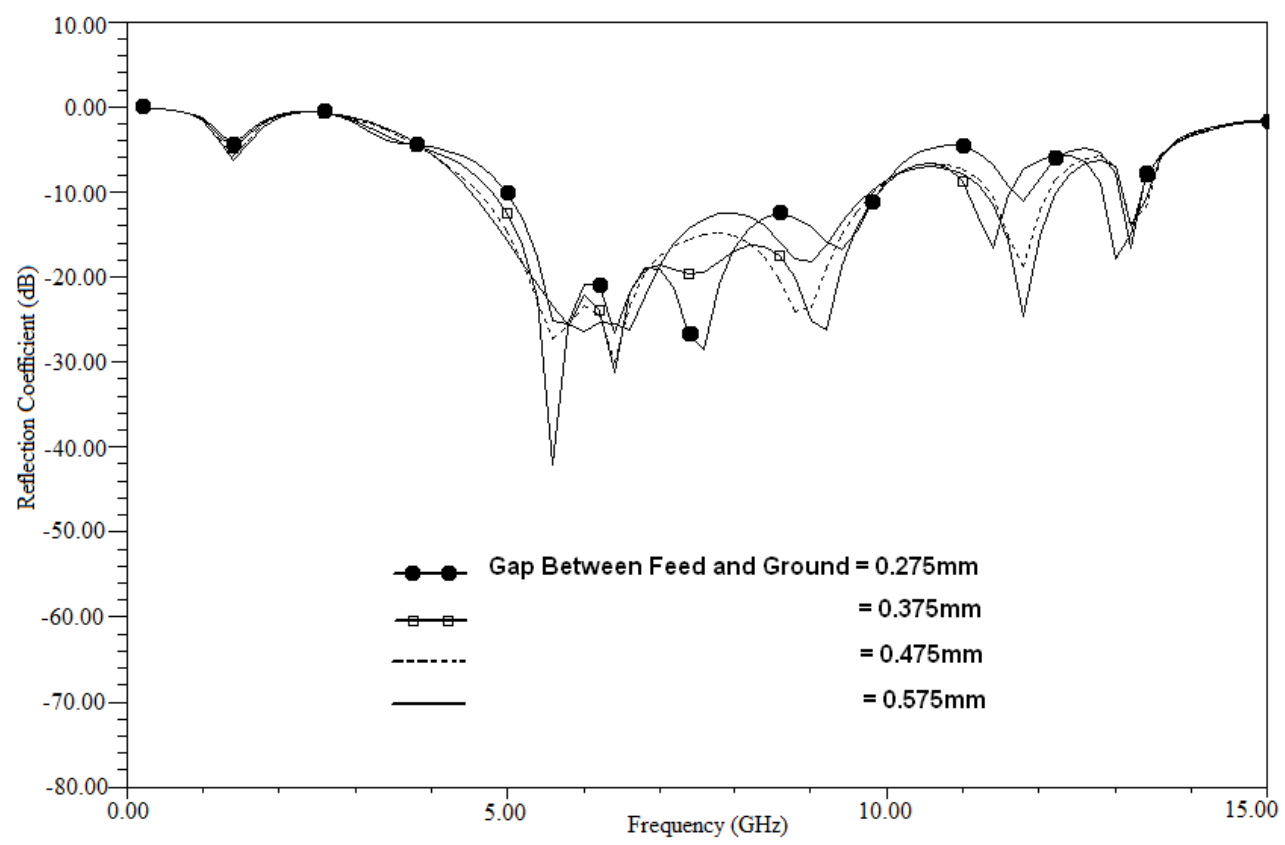

Fig. 5. Simulated results of various gap between feed and ground

\section{Effect of Gap between patch and ground}

The proposed tree-type fractal antenna has also been simulated for the gap between patch and ground. This gap is very critical for the proper coupling of EM energy for wide bandwidth because the current density resides more on edge of patch and on the ground edges near the patch. The simulated result for the various gaps is shown in Fig. 6 for $0.48 \mathrm{~mm}$ to $1.08 \mathrm{~mm}$ with the step of 0.2 $\mathrm{mm}$. As the gap between patch and ground increases the matching at lower end frequency improves. The overall bandwidth of the antenna increases. The optimum gap between the patch and ground has been achieved $0.68 \mathrm{~mm}$ for this proposed antenna. As this gap further increases the impedance matching in the operating band starts deteriorate. 


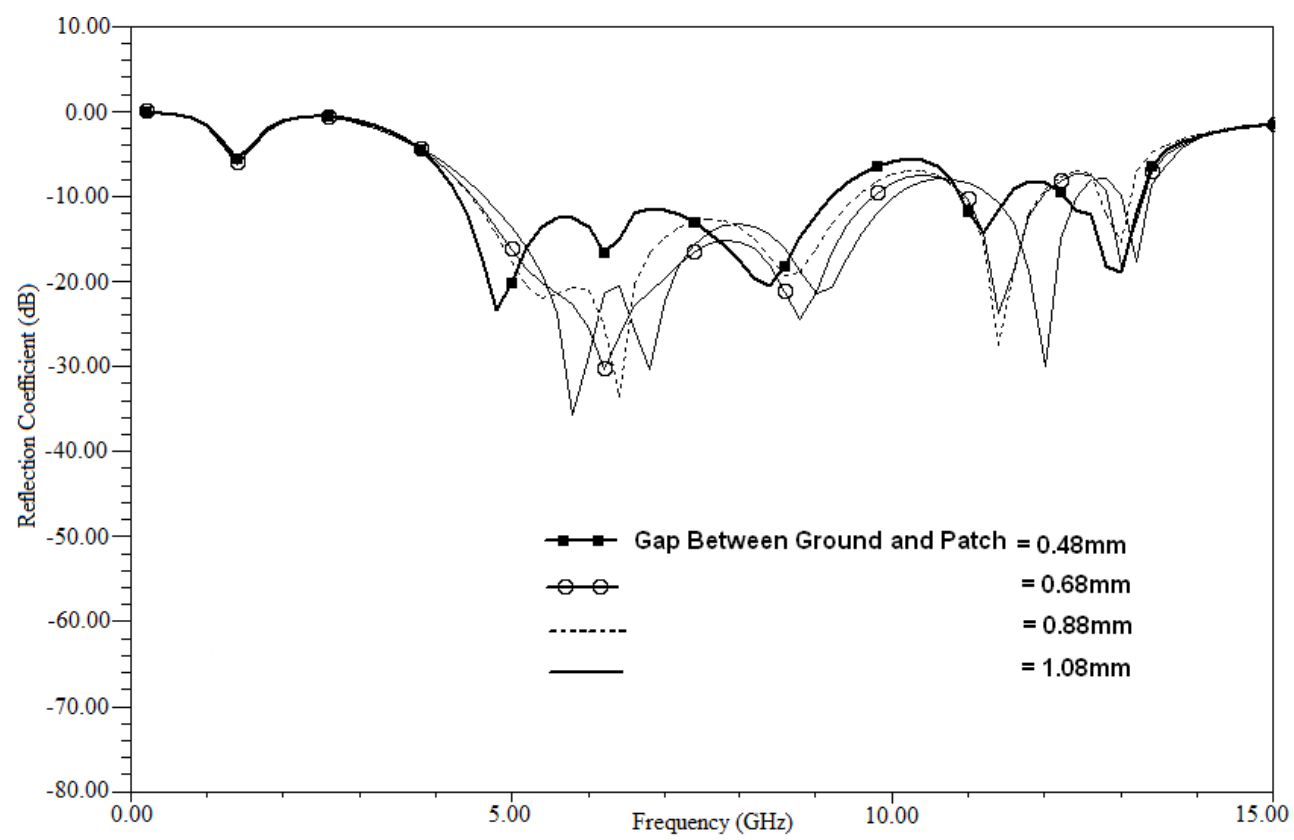

Fig. 6. Simulated results of various gap between ground and patch

\section{Effect of the Ground Plane Length}

The proposed tree-type antenna has been fed with CPW-feed as shown in Fig. 2. In the proposed antenna, the ground shape is rectangular shape. In the CPW-feed antenna, the rectangular ground plane, feed and radiating patch all are on same side of substrate. In the CPW - feed monopole antenna, the length of the ground plane is very important. The proposed antenna has been simulated for various length of the ground. The length of the ground is optimized. The simulated results of various length of the ground are shown in Fig. 7. It has been optimized with the step of $2 \mathrm{~mm}$ from $11.9 \mathrm{~mm}$ to $15.9 \mathrm{~mm}$ ground length. A little frequency shift is observed at lower frequency side and almost no effect at higher frequency side. This indicates the ground length effect is insignificant. The optimized length for this antenna is achieved $13.9 \mathrm{~mm}$. The quarter wavelength of the ground plane of antenna at $5.0 \mathrm{GHz}$ is $15.0 \mathrm{~mm}$. With this optimized ground length, antenna exhibits the proper bandwidth. Now, overall size of antenna is $31 \mathrm{~mm}$ x $32 \mathrm{~mm}$. 


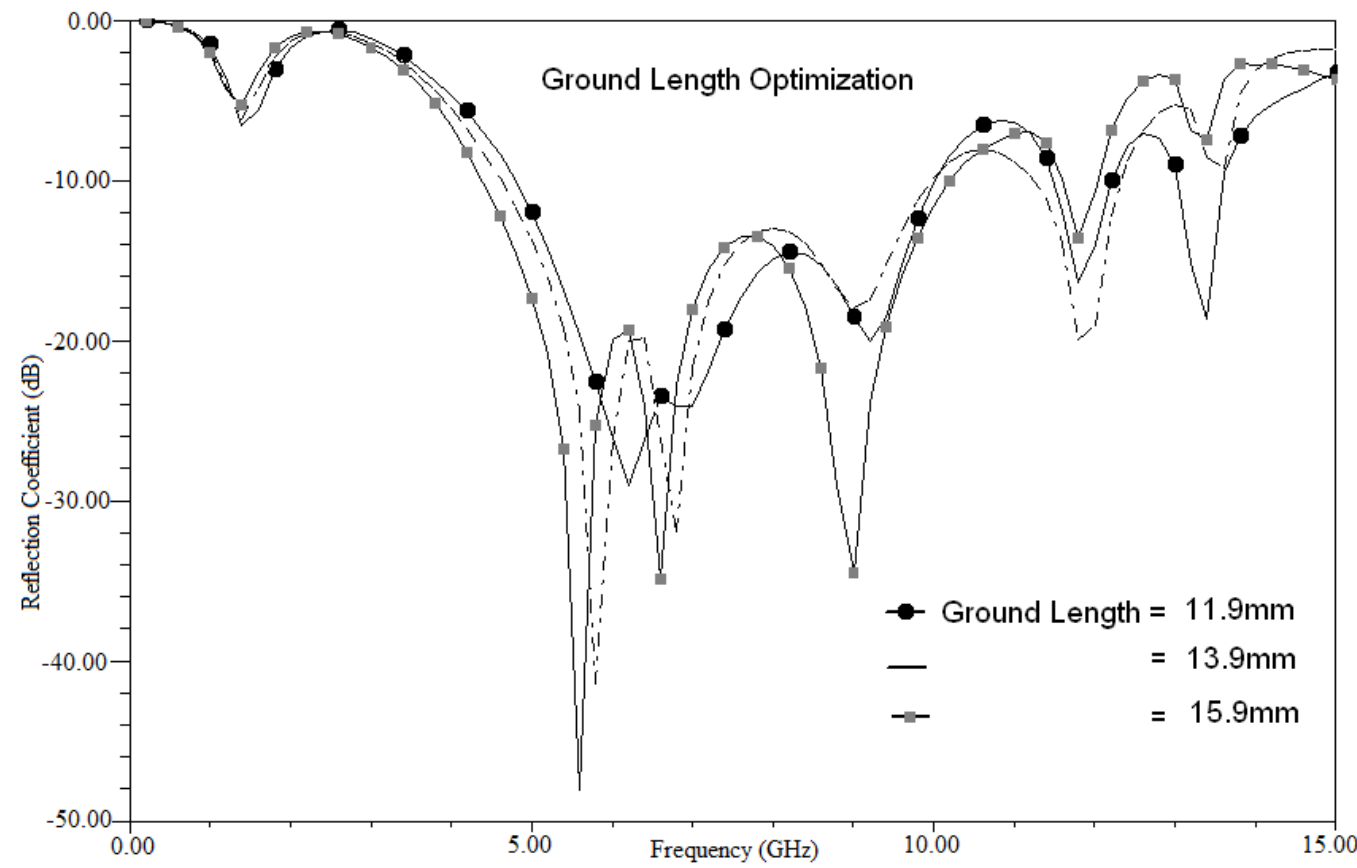

Fig. 7. Simulated results of various ground length

\section{E. Effect of the Ground Plane Width}

Here, the width of the ground plane of proposed tree-type fractal antenna has been optimized and its effect on the antenna bandwidth has been observed. The proposed antenna has been simulated for various ground plane width from $11.425 \mathrm{~mm}$ to $15.425 \mathrm{~mm}$ with step of $2 \mathrm{~mm}$ as shown in Fig. 8. It is observed as the ground width increases, the first resonant frequency slightly shifted to lower frequency side. The width effect is also observed at higher frequency. There is an optimum value of width for wide impedance matching. The ground width affects the impedance matching in the full band because ground acts as a resonant circuit. For proper matching and compact size of antenna, the optimized one side ground width has been achieved $13.425 \mathrm{~mm}$ by fixing all others optimized parameters. 


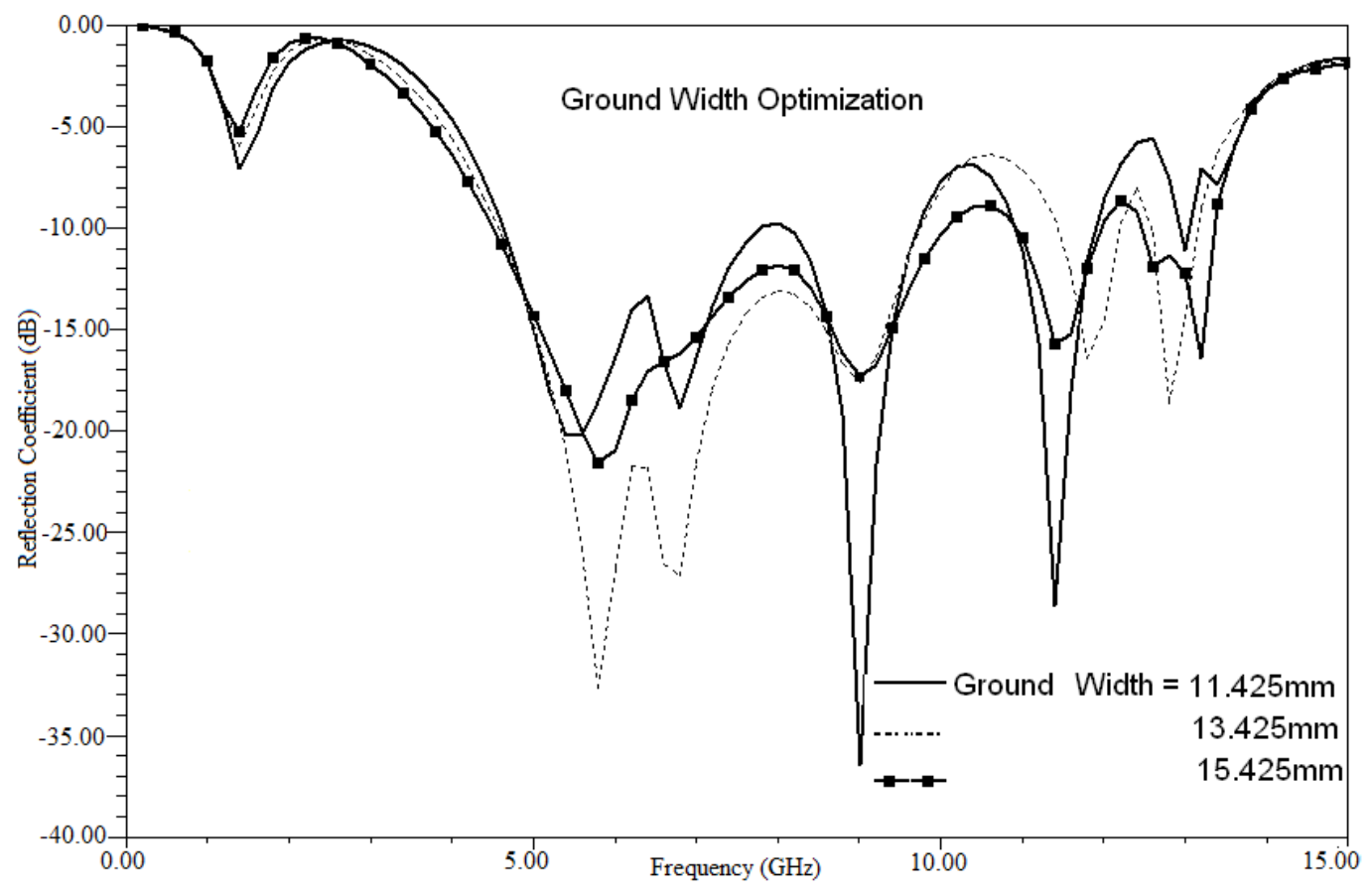

Fig. 8. Simulated results of various ground width

\section{EXPERIMENTAL RESULTS AND DISCUSSION}

The proposed fractal antenna has been fabricated with optimized dimension as shown in Fig. 2. The antenna has been tested using R \& S VNA ZVA40. The experimental result of proposed antenna exhibits the excellent UWB characteristics from $4.9 \mathrm{GHz}$ to $14.0 \mathrm{GHz}$ at VSWR 2:1. It corresponds to $96.296 \%$ impedance bandwidth. The antenna is simulated using EM simulator HFSS with optimized dimension. The experimental and simulated results are in close agreement as shown in Fig. 9. The experimental result slightly varies from the simulated result. This may be due to the tolerance in manufacturing, uncertainty of the thickness and the dielectric constant and lower quality of SMA connector (VSWR $=1.3$ ). The differences between simulated and experimental values may also be caused due to the soldering effects of an SMA connector, which have been neglected in our simulations. The SMA connector is not taken into account in all of the simulations so as to ease the computational requirements. It is noticed that this SMA port mainly affects the higher order resonances by shifting their resonant frequencies.

The peak gain of this proposed antenna has also been simulated and shown in Fig. 10. The peak gain of this antenna increases as the frequency increase. This is because the effective area of the antenna increases at the higher frequency because of shorter wavelength at high frequency. Beyond 14.0 $\mathrm{GHz}$, the peak gain of antenna starts decreasing because reflection coefficient becomes poor beyond $14.0 \mathrm{GHz}$. The maximum value of peak gain is around $6 \mathrm{dBi}$ at $11.5 \mathrm{GHz}$. 


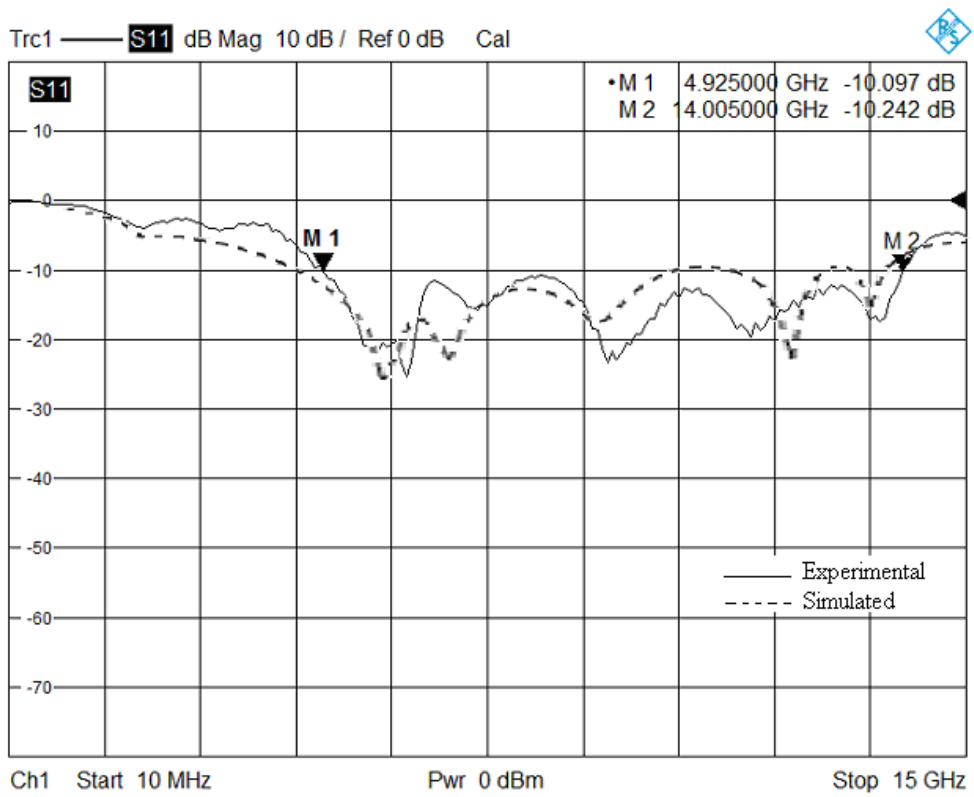

Fig. 9. Experimental and simulated result of proposed antenna

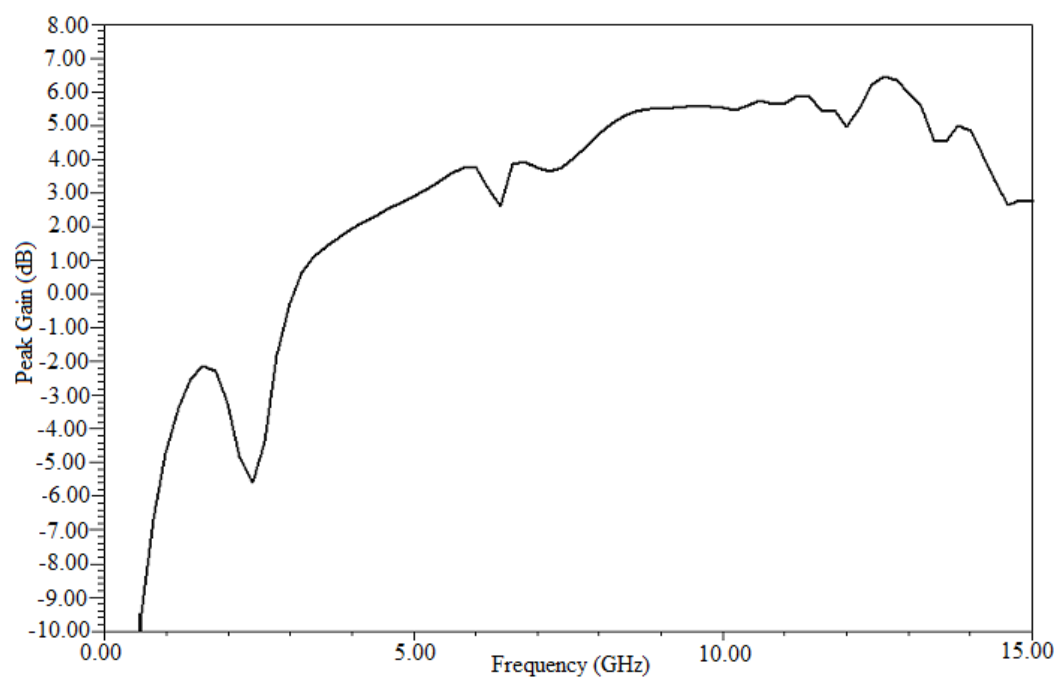

Fig. 10. Simulated peak gain of proposed antenna with respect to its iteration

\section{RADIATION PATTERNS}

The antenna radiation of this proposed tree-type fractal antenna has been simulated at selective frequencies $4.8 \mathrm{GHz}, 6.0 \mathrm{GHz}$ and $8.0 \mathrm{GHz}$. The $\mathrm{E}$ and $\mathrm{H}$ - plane radiation patterns on these frequencies are shown in Fig. 11, 12 and 13 respectively. The nature of the radiation patterns in $\mathrm{H}$ plane are nearly omni - directional throughout the band. In E-plane, natures of radiation patterns are figure of eight or bidirectional. The radiation patterns in the $\mathrm{E}$ and $\mathrm{H}$-plane are almost stable throughout the band except some slight variation. 


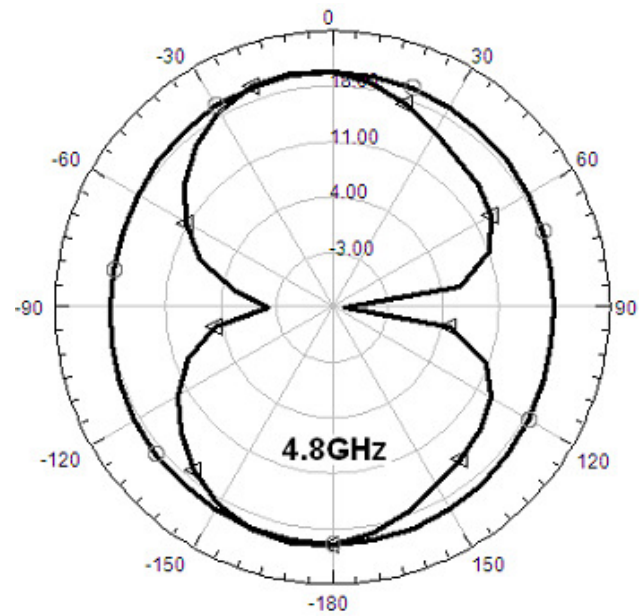

Fig. 11. Simulated $\mathrm{E}$ and $\mathrm{H}-$ plane radiation pattern of proposed antenna at $4.8 \mathrm{GHz}$

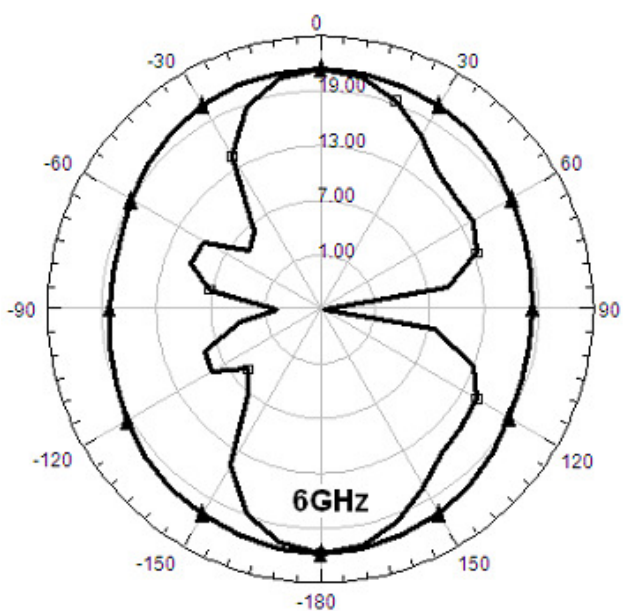

Fig. 12. Simulated E and H-plane radiation pattern of proposed antenna at $6.0 \mathrm{GHz}$

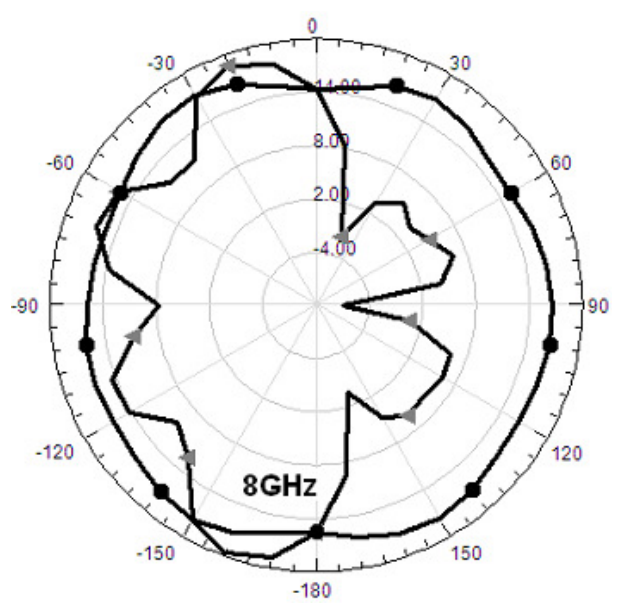

Fig. 13. Simulated $\mathrm{E}$ and $\mathrm{H}$-plane radiation pattern of proposed antenna at $8 \mathrm{GHz}$

VI. GROUP DELAY AND PHASE VARIATION 
The studies of group delay and phase variation are important parameters for UWB system. The group delay has been measured by putting two identical antennas face to face at $30 \mathrm{~cm}$ distance in far field region. The experimental group delay versus frequency is shown in Fig. 14. The group delay is less than $1.5 \mathrm{~ns}$ in the operating frequency band with two identical antennas. Actually, it will be half of the calculated group delay using two antennas i.e $0.75 \mathrm{~ns}$. It is observed that group delay is almost constant throughout the band. It means variation in the phase is negligible. This indicates the phase linearity. This phase linearity of antenna is important in UWB system to transmit/receive the high data rate pulse without distortion.

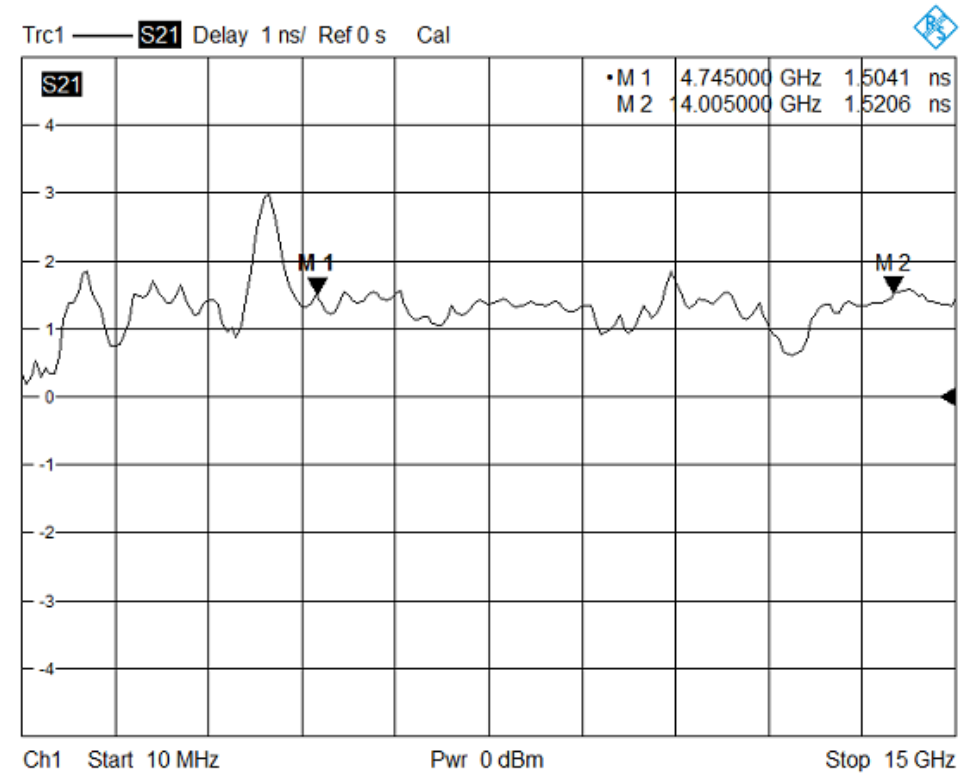

Fig. 14. Experimental group delay of proposed antenna by using two identical antennas at $30 \mathrm{~cm}$

\section{BACKSCATTERING OF PROPOSED ANTENNA}

The study of backscattering is important because antenna contributing significantly in the total RCS of low observable platforms. The RCS of fractal antenna is dependent on the short circuit, open circuit and matched load termination. The short circuit and open circuit termination gives antenna mode scattering. The structural mode scattering can be calculated with matched load termination. The simulated results of monostatic RCS for open, short and matched load termination are shown in Fig. 15. It is observed at higher frequency, the monostatic RCS reduces because the size of object become more than the wavelength. Similarly, at lower frequency the RCS is maximum because object size is less that the operating wavelength. 


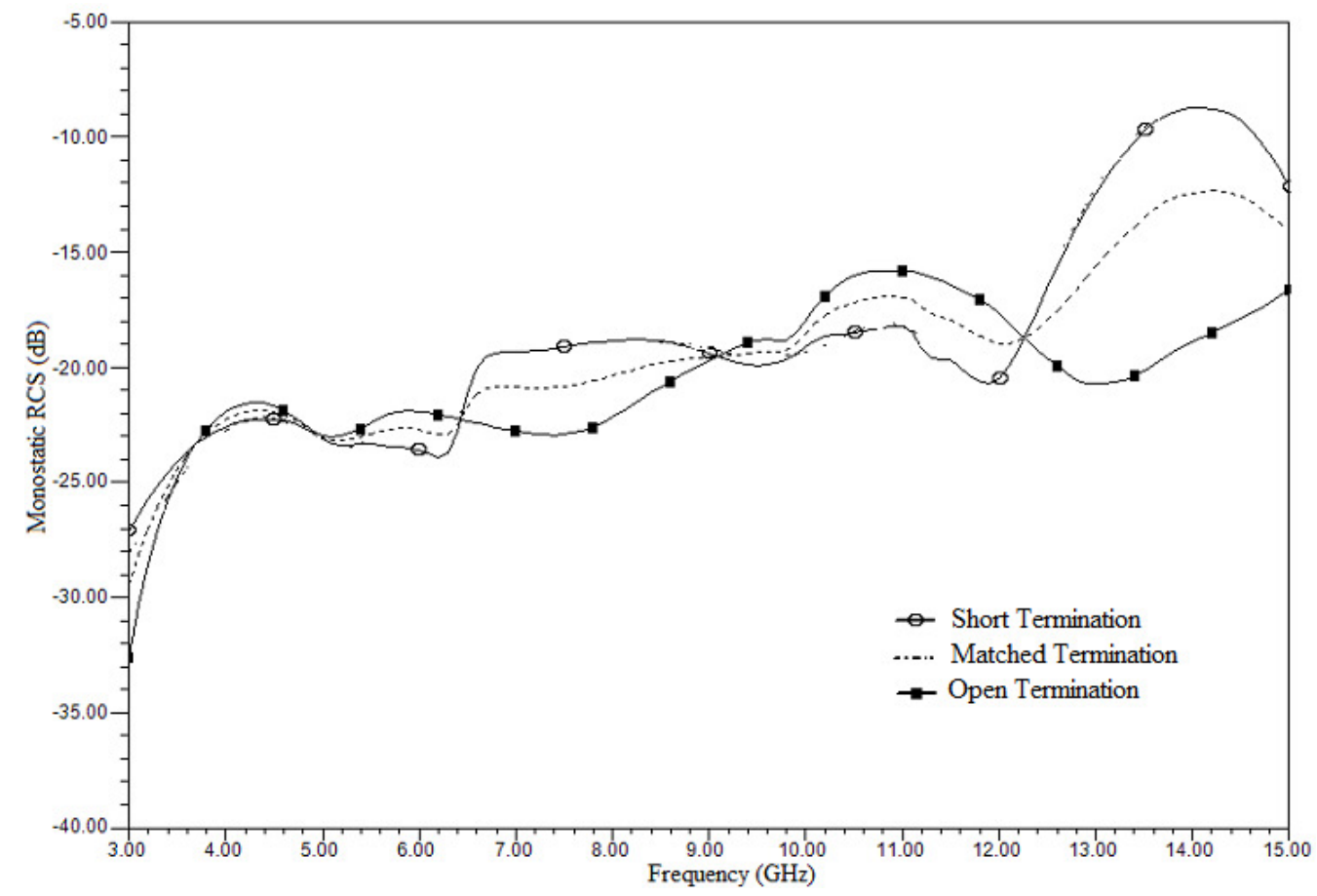

Fig. 15. Simulated results of short, open and matched load termination

The total RCS $(\sigma)$ of an antenna are divided into two part i.e. RCS of structural mode $\left(\sigma_{s}\right)$ and antenna mode $\left(\sigma_{a}\right)$. They are related to each other by $\sigma=\mid \sqrt{ }\left(\sigma_{\varepsilon}\right)+\sqrt{\left.\left(\sigma_{a}\right) e^{j *}\right|^{2}}$ where $\Phi$ is the phase difference between these two modes [13]. The antenna scattering can be calculated for the proposed antenna by using the model proposed in [14]. The antenna scattering for antenna mode and scattering mode can be calculated using following expression

$$
\sqrt{\sigma}=\sqrt{\sigma_{s}}+\sqrt{\sigma_{a}} e^{j \phi}
$$

Where, $\sigma=$ total RCS of Antenna

$$
\begin{aligned}
& \sigma_{s}=\text { RCS of Structural Mode } \\
& \sigma_{a}=\text { RCS of Antenna Mode }
\end{aligned}
$$

For Open Circuit termination,

$$
\sqrt{\sigma_{o}}=\sqrt{\sigma_{s}}+\sqrt{\sigma_{a}} e^{j \phi}
$$

For Short Circuit termination,

$$
\begin{aligned}
& \sqrt{\sigma_{s h}}=\sqrt{\sigma_{g}}+\sqrt{\sigma_{a}} e^{j(\phi+\pi)} \\
& \sqrt{\sigma_{s h}}=\sqrt{\sigma_{s}}-\sqrt{\sigma_{a}} e^{j \phi}
\end{aligned}
$$

From equations (2) and (3), the structural mode and antenna mode scattering can be calculated 


$$
\sigma_{g}=\left|\frac{\left(\sqrt{\sigma_{0}}+\sqrt{\sigma_{\operatorname{sh}}}\right)}{2}\right|^{2}
$$

For antenna mode scattering

$$
\sigma_{a}=\left|\frac{\sqrt{\sigma_{0}}-\sqrt{\sigma_{a} h}}{2}\right|^{2}
$$

In conclusion, the RCS of Structural Mode is the RCS of matched load termination and can also be calculated from equation (4). It is verified from equation (4) and matched load termination. The antenna mode scattering can be calculated from equation (5) using the RCS of open and short Circuit termination. The monostatic RCS with open and short termination is calculated using HFSS. The calculated monostatic RCS for each iteration is shown in Fig. 16. It is observed the monostatic RCS of proposed antenna ( $3^{\text {rd }}$ iterative antenna) is greatly reduces above $13 \mathrm{GHz}$. This reduction of RCS is justified from experimental reflection coefficient which becomes poor above $13 \mathrm{GHz}$. The monostatic RCS is also calculated with respect to aspect angle. The antenna mode scattering RCS with respect to aspect angle can be calculated from monostatic RCS with short and open circuit termination as shown in Fig. 17 at $5 \mathrm{GHz}$. It is observed monostatic RCS for antenna mode scattering versus aspect angle varies as aspect angle vary.

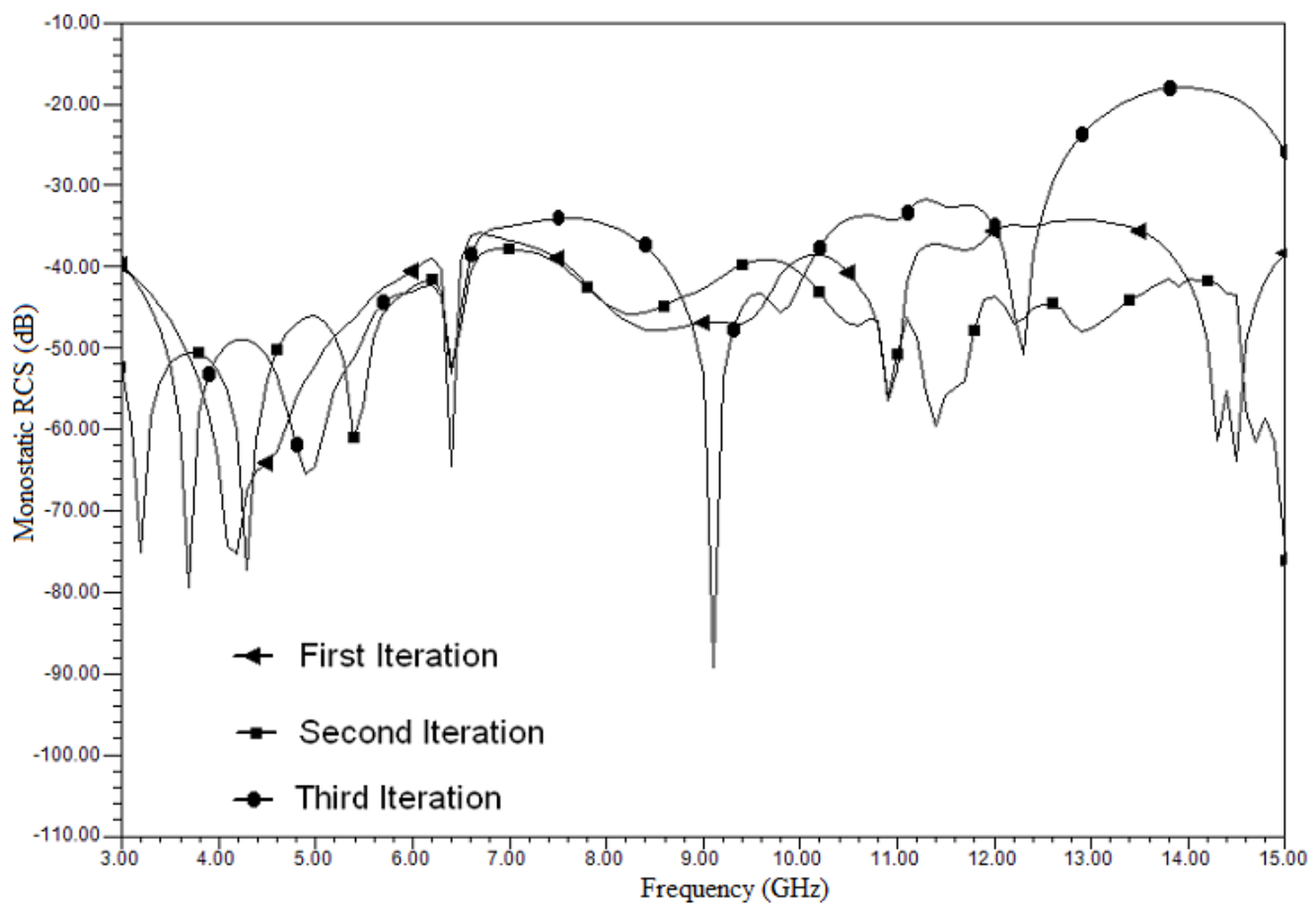

Fig. 16. Simulated results of antenna mode scattering for each iteration 


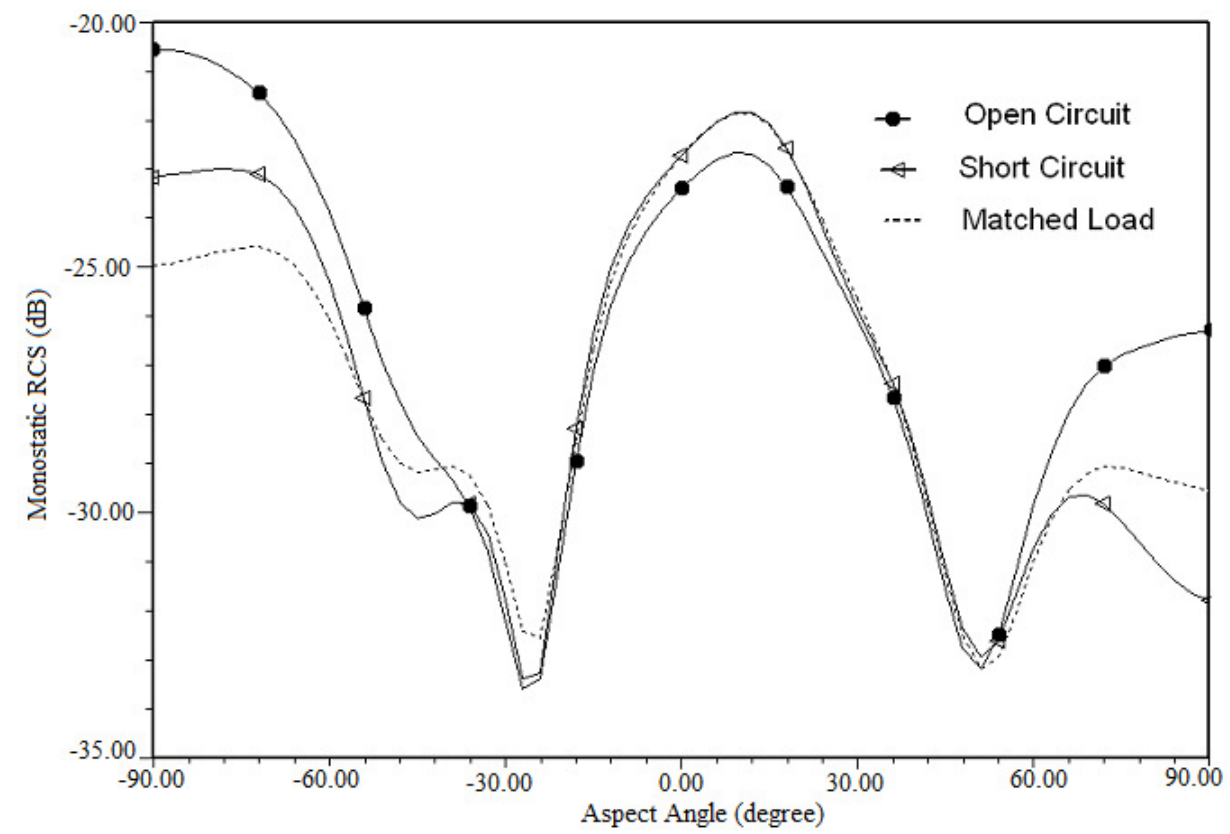

Fig. 17. Simulated results with short, open and matched termination versus aspect angle

\section{CONCLUSIONS}

The proposed tree-type fractal antenna has designed and implemented experimentally. The antenna exhibits 96.297\% impedance bandwidth. To achieve UWB characteristics from $5.825 \mathrm{GHz}-10.6$ GHz for DS-CDMA system, the effects of various design parameters have been studied thoroughly. The simulated results are found in good agreement with experimental results. The radiation pattern of the antenna is omni-directional in H-plane and bidirectional in E-plane. The group delay of this antenna is less than $0.75 \mathrm{~ns}$. The phase variation is almost negligible throughout the band. The backscattering of this antenna is good through the operating band. This makes the antenna strong candidate for secure and military applications. This antenna is simple to fabrication, compact in size, easy to integrate with the device and MIC/MMIC circuits. Such type of antenna is useful for UWB DS-CDMA system, microwave imaging and vehicular radar.

\section{ACKNOWLEDGEMENT}

Authors are grateful to the Vice Chancellor, Pro-Vice Chancellor, Dean (Acd) of Defence Institute of Advanced Technology (Deemed University), Pune, India for permitting to publish this work. Author is also thankful to the colleague of the Department of Electronics Egg. for timely support and cooperation.

\section{REFERENCES}

[1] G. Breed, "A summary of FCC rules for UWB communications," High Frequency Electronics, pp. 42-44, Jan. 2005.

[2] L. Yang and G. B. Giamalkis, "UWB Communications," IEEE signal processing Magazine, pp. 26-28, Nov. 2004. 
[3] International Telecommunication Union, Radio communication Study Groups, "Framework for the introduction of devices using ultra-wideband technology," Document 1/85(Rev.1)-E, 09, Nov. 2005.

[4] Kamya Yekeh Yezdandoost and Ryuji Khono "UWB antenna," IEEE radio communication , pp. 529-532, Jun. 2004.

[5] D. H. Werner and S. Ganguly, "An Overview of Fractal Antenna Engineering Research," IEEE, Antenna and Propagation Magazine, Vol. 45, No. 1,38-57,2003.

[6] N.Cohen, "Fractal Antenna Applications in Wireless Telecomm.," Proceeding Professional Program Elect. Industry Forum pp. 43-49, 1997.

[7] M. R. Haji-Hashemi, M. Mir-Mohammad Sadeghi, and V. M. Moghtadai,'Space-filling patch antennas with CPW -feed," Progress in Electromagnetic Research Symposium, March 26-29, 2009.

[8] Edward Lule, Tadeusz Babij, and Time Derivative, "Koch Island Fractal Ultra Wideband Dipole Antenna," IEEE Antennas and Propagation Society International Symposium, Vol.3, 20-25, June 2004, pp. 2516 - 2519.

[9] Raj Kumar et. al.,'On the design of inscribed triangle non-concentric circular fractal antenna,", MOTL, Vol.52, No. 12, Dec. 2010.

[10] Raj Kumar et. al.,'Design of CPW-fed fourth iterative UWB fractal antenna," International Journal of Microwave and optical Technology, Vol.6, No. 5, pp. 320-327, Nov 2010.

[11] E. F. Knott, et. al., "Radar Cross Section," 2nd edition, SciTech, Raleigh, NC, 2004.

[12] D. Pozar, "Radiation and scattering from a microstrip patch on a uniaxial substrate," IEEE Trans. Antennas Propag., Vol. 35,No. 6, pp. 613-621, 1987.

[13] Y. Liu and S. X. Gong, "A novel UWB clover-disc monopole antenna with RCS reduction," Journal of Electromagnetic Waves and Applications, Vol. 22, No. 8-9, pp. 1115-1121, 2008.

[14] S. Hu, H. Chen, C. Law, Z. Shen, L. Zhu, W. Zhang, and W. Dou, "Backscattering cross section of ultra wideband antennas," IEEE Antennas and Wireless Propagation Letters, Vol. 6, pp. 70-73, 2007. 